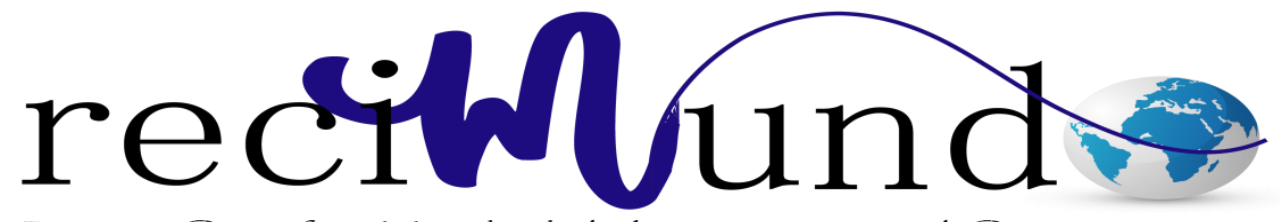

Revista Científica Mundo de la Investigación y el Conocimiento

Digna Roció Mejia Caguana a ; Carlos Jeovanny Tacle Estrada ${ }^{\text {b}}$; Benavides Selllán Luis Ernesto ${ }^{c}$; Sofía Verónica Vásconez Miranda ${ }^{\mathrm{d}}$

Los transtorno del aprendizaje y el modelo pedagógico invertido

Revista Científica Mundo de la Investigación y el Conocimiento. Vol. 2 núm.2, mayo, ISSN: 2588-073X, 2018, pp. 194-208

DOI: 10.26820/recimundo/2.(2).2018.194-208

Editorial Saberes del Conocimiento

Recibido: 05/12/2017

Aceptado: $15 / 02 / 2018$

a. Universidad de Guayaquil; digna.mejiac@ug.edu.ec

b. Universidad de Guayaquil; carlos.taclee@ug.edu.ec

c. Universidad de Guayaquil; luis.benavidess@ug.edu.ec

d. Universidad de Guayaquil; sofia.vasconezm@ug.edu.ec 


\section{Los transtorno del aprendizaje y el modelo pedagógico invertido}

Vol. 2, núm. 2., (2018)

Digna Rocio Mejia Caguana; Carlos Jeovanny Tacle Estrada; Benavides Selllán Luis Ernesto;

Sofía Verónica Vásconez Miranda

\section{RESUMEN}

La investigación direcciona a los docentes, hacia el Modelo Pedagógico Aula invertida, para el desevolvimiento acádemico, durante el proceso de enseñanza aprendizaje. Porque se ha evidenciado que existen varios transtornos realacionados, que afectan al interaprendizaje eficaz y a la autoestima estudiantil, entre ellas la Disortografía dificultad para aplicar las normas ortográficas, la Dislexia alteración en la capacidad de leer, el transtorno por déficit de atención con hiperactividad (TDAH) y la Disgrafía dificultad en la escritura. Problemáticas que se dan con mayor escala en la primera etapa escolar y persisten en la educación media. Los posibles orígenes según investigaciones están basadas en el cerebro. Sin embargo, no son causas únicas, también se cuestiona al factor ambiental, situaciones ocurridas en la infancia y trastornos hereditarios. Para la comprobación eficaz de la información recopilada y procesada se usó el método Inductivo-deductivo, los instrumentos, se basó en una observación aúlica y una encuesta a 100 personas entre docentes del área de Lengua y Literatura y estudiantes de la UEF Dr. Miguel Donoso Pareja, estableciendo gráficos estadísticos. Para la documentación se recurrió a la bibliografía de varios científicos, pedagógos, psicólogos y filósofos, como es la Taxonomía de Bloom, quien justifica, al repaso de contenidos como una tarea cognitiva de bajo nivel y que la práctica de actividades implica tareas de alto nivel. Según Vygotsky, el papel de los adultos es de apoyo, dirección y organización del aprendizaje. Con este estudio se prevé impulsar la lectoescritura a través de las TICS.

Palabras clave: Disortografía, Dislexia, Disgrafía, Aula invertida, Tics. 


\section{Los transtorno del aprendizaje y el modelo pedagógico invertido}

Vol. 2, núm. 2., (2018)

Rodrigo del Pozo Durango; Juan Manuel Galarza S; Washington Fierro Saltos; Juan Sosa Silva Digna Rocio Mejia Caguana; Carlos Jeovanny Tacle Estrada; Benavides Selllán Luis Ernesto; Sofía Verónica Vásconez Miranda

\section{ABSTRACT}

The research directs the teachers, towards the inverted Classroom Pedagogical Model, for the development of the reading and writing, during the teaching-learning process. Because it has been shown that there are several reactivated disorders that affect effective inter-learning and student self-esteem, including dystortography, difficulty in applying spelling rules, dyslexia, impairment in reading ability, attention deficit hyperactivity disorder (ADHD). , Dysgraphy difficulty in writing, etc. Problems that occur with the largest scale in the first stage of school and persist in secondary education. The possible causes according to investigations are based on the brain. However, there are no unique causes, the environmental factor is also questioned, situations that occurred in childhood and hereditary disorders. The Inductive-deductive method was used for the effective verification of the information collected and processed. The instruments, was based on an observation and a survey of 100 people between teachers of the area of Language and Literature and students of the UEF Dr. Miguel Donoso Pareja, establishing statistical graphs. For documentation, the bibliography of several scientists, pedagogues, psychologists and philosophers was used, such as Bloom's Taxonomy, which justifies reviewing the contents as a low-level cognitive task and that the practice of activities involves high-level tasks. According to Vygotsky, the role of adults is to support, direct and organize learning. With this study, literacy can be improved through TIC.

Key words: Disortography, Dyslexia, Dysgraphia, Inverted classroom, Tics. 


\section{Los transtorno del aprendizaje y el modelo pedagógico invertido}

Vol. 2, núm. 2., (2018)

Digna Rocio Mejia Caguana; Carlos Jeovanny Tacle Estrada; Benavides Selllán Luis Ernesto;

Sofía Verónica Vásconez Miranda

\section{Introducción.}

La década de los ochenta marcó a la humanidad con grandes paradigmas, el pensamiento de esta generación, se sumergió en el boom tecnológico, la economía industrial se vió plagada de aparatos mecánicos, que necesitaban menos personal obrero, los empresarios adquierieron máquinas, para el proceso de la información e incluso para crear, monitorear y controlar sus productos automáticamente. (Arduini, Aparecida Capellini, \& Ciasca, 2006)

Desde esta época el auge tecnológico, no ha dejado de sorprender al mundo, su aplicación se ha reducido en nanotecnología y se ha multiplicado en velocidades de años luz. Esto ha significado una gran eminencia de coyunturas, pero también ha originado magnos abismos incontrolables, especialmente en la educación, las tareas escolares se han reducido a dar un clic, copiar y pegar, la caligrafía se ha minimizado a un print, en matemáticas es infaltable el dispositivo de cálculo, no hay un hábito lector, por cuanto el Ministerio de Educación, durante el periodo 2017-2018, implementó el Proyecto Escolar "Yo Leo", este programa permitió alimentar la comunicación verbal, escrita y comprensiva, práctica que se debe continuar implementando no solo en el área de lengua sino en todas las asignaturas, porque se encontraron graves y cuantiosas falencias. (Ajuriaguerra, 1973)

El trabajo de investigación se centra en identificar los trastornos de aprendizaje que recae en la lectoescritura y las falencias gramaticales existentes, en los estudiantes de noveno año de la UEF Dr. Miguel Donoso Pareja, después de ejecutar las observaciones aúlicas se detectó, que más alla de situaciones especiales, el problema de la lectoescritura, esta direccionada a los malos hábitos del uso del lenguaje oral y escrito, los jóvenes no se expresan correctamente, utilizan 


\section{Los transtorno del aprendizaje y el modelo pedagógico invertido}

Vol. 2, núm. 2., (2018)

Rodrigo del Pozo Durango; Juan Manuel Galarza S; Washington Fierro Saltos; Juan Sosa Silva Digna Rocio Mejia Caguana; Carlos Jeovanny Tacle Estrada; Benavides Selllán Luis Ernesto; Sofía Verónica Vásconez Miranda

frases no acordes con el idioma y su escritura es casi ilegible. (Guevara Benítez, López H, \& García V, 2008) señala que "el nivel del desarrollo del vocabulario, es tanto en contenido, como en cantidad, la experiencia y familiarización con una variedad de estilos conversacionales, las habilidades de comprensión del lenguaje hablado, y la capacidad para reflexionar sobre el lenguaje que se utiliza"

Entre las dificultades de la lectoescritura, están los fonemas sonidos de las letras y los grafemas se presentan en la forma escrita de las letras, las cuales se asocian al aprendizaje lector dislexia, las de carácter lecto-mecánico cuando la lectura es lenta e insegura con frecuentes errores. Según estudios, para estar en el plano de dificultad, estas deben estar por debajo de lo esperado dada la edad cronológica del niño, su coeficiente de inteligencia, así como el grado de escolaridad propia a su edad evolutiva. También están las dificultades lectoras cuando interfieren significativamente en el rendimiento y en todas sus actividades psicomotrices.

Es global el automatismo, por ello es común ver a los estudiantes acceder y manejar con facilidad miles de aplicaciones, la mayoría de ocio, que les hace dependientes y adictos a la tecnología, comprobando que el abuso inconsciente de estos recursos y la interacacción no confiable con pseudos amigos han provocado que se quebrante su léxico y escritura.

\section{Incidencia del modelo de aula invertida en la lectoescritura}

Hoy hablar de educación tecnológica es imprescindible, considerándose que los estudiantes son nativos tecnológicos y no se generan problemáticas ante la aparición de nuevos recursos informáticos, porque cada vez son más accesibles y no requieren de ciencia para su 


\section{Los transtorno del aprendizaje y el modelo pedagógico invertido}

Vol. 2, núm. 2., (2018)

Digna Rocio Mejia Caguana; Carlos Jeovanny Tacle Estrada; Benavides Selllán Luis Ernesto;

Sofía Verónica Vásconez Miranda

aplicación. Los cuales están clasificados y adheridos a diferentes campos específicos, existen varios grupos referentes al término educativo-tecnológico, entre ellas las Tecnologías de la información y la comunicación (TICs), las Tecnologías del aprendizaje y del conocimiento (TAC) y las Tecnologías del empoderamiento y la participación (TEP).

Estos referentes tecnológicos dan soporte a la educación del milenio, porque inciden en la inserción del modelo de Aula Invertida, con él se prevé fructificar la lectoescritura en los estudiantes, creando ambientes de aprendizaje, creativo, constructivo y cognositivo a su vez incrementando el léxico y optimizando la caligrafía. "Brunner es importante tener ayudas para la enseñanza, manejar dispositivos que permitan y faciliten el descubrimiento y el aprendizaje”. (Posada, 1993)

El Aula invertida es un modelo de enseñanza que consiste en dar lecciones y tareas anticipadas a través de recursos multimedia, cuyo contenido debe ser lo más práctico e idóneo, para que los estudiantes puedan ilustrarse con estas herramientas en el menor tiempo posible e interactuar con el docente durante la hora clase.

\section{Importancia del problema}

La buena práctica docente sobre las TICs, enriquecen los contenidos académicos a través de las múltiples fuentes de información que ofrece el internet, para la escritura se propone el uso de las herramientas de office, que le permitirá concentrarse en la corrección ortográfica y la excelente presentación de trabajos. La lectura se pretende acresentar mediante escritos, imágenes y videos hipermediales. Los trabajos en equipo se fomentarán, con el buen uso de las redes sociales y entornos web 3.0. Con la finalidad de transformar el interprendizaje 


\section{Los transtorno del aprendizaje y el modelo pedagógico invertido}

Vol. 2, núm. 2., (2018)

Rodrigo del Pozo Durango; Juan Manuel Galarza S; Washington Fierro Saltos; Juan Sosa Silva Digna Rocio Mejia Caguana; Carlos Jeovanny Tacle Estrada; Benavides Selllán Luis Ernesto; Sofía Verónica Vásconez Miranda

implementando el Modelo pedagógico Aula Invertida como estrategia para salvaguardar el correcto uso del idioma español.

Uno de los fenómenos más frecuentes de la disciplina lingüística, es que pese a que millones de personas pueden hablar el mismo idioma, es frecuente observar que no hablan de la misma forma formándose los llamados léxicos regionales, léxicos generacionales, préstamos léxicos y la aparición del Espanglish. Las jergas o argots, surgieron al juntarse diferentes comunidades, en otros casos por diferencias sociales, otro fenómeno es el yeísmo, orígenes del idioma español es que la 'll' y la 'y' representaban dos fonemas distintos. La importancia es determinar hasta qué punto cada uno de estos léxicos se deben utilizar.

\section{Rasgos de la disortografía}

Los trastornos de la lectura están asociados a la disortografía, son visible en niños de una edad temprana y suelen especificarse de acuerdo como su cerebro procesa el lenguaje, a pesar que no todos tendrán el mismo grado de asimilación, en ciertos casos no reconocen palabras que ya conocen, en otros casos se les complican al deletrear las palabras, existen más complicaciones como por Ej... Problemas para leer, dificultad para escribir en letra manuscrita, problemas para entender la palabra escrita y dificultad para leer con rapidez

Cabe resaltar que los trastornos de la lectura no son signos de baja inteligencia, los estudiantes con trastornos de la lectura podrían tener otras discapacidades de aprendizaje, que pueden caracterizarse en la escritura o los números. 


\section{Los transtorno del aprendizaje y el modelo pedagógico invertido}

Vol. 2, núm. 2., (2018)

Digna Rocio Mejia Caguana; Carlos Jeovanny Tacle Estrada; Benavides Selllán Luis Ernesto;

Sofía Verónica Vásconez Miranda

El desarrollo verbal dependerá no sólo de los requisitos instrumentales (audición, motricidad fonoaudiológica) y del aspecto cognitivo, sino del desarrollo de los componentes del lenguaje (fonología, léxico y sintaxis) y funcionales (semántica-significado) y la pragmática (uso contextualizado y social). (Arduini, Aparecida Capellini, \& Ciasca, 2006)

Los transtornos asociados a la disortografía se prescriben en cinco factores.

Perceptivo: presencia de dificultades en la percepción y la memoria, está asociado al sentido Auditivo - Visual que puede ser Espacial - Temporal.

Intelectual: percnota inmadurez intelectual y exige prácticas elocuentes en el aprendizaje de los fonemas, grafemas, sílabas, palabras y frases.

Lingüístico: muestra problemas en el habla al pronunciar sonidos, está vinculado al lenguaje articulatorio el cual evita la percepción del sonido, interviniendo en el grafismo.

Afectivo: El estudiante requiere motivación, para evitar que cometa errores de gran escala.

Pedagógico: Determina cambios en los métodos de enseñanza.

\section{Detección disortográfica}

Para detectar la disortografía se hace un diagnóstico, luego se revisa minuciosamente, las faltas cometidas, con la finalidad de brindar la ayuda necesaria al estudiante, siga los siguientes puntos: 


\section{Los transtorno del aprendizaje y el modelo pedagógico invertido}

Vol. 2, núm. 2., (2018)

Rodrigo del Pozo Durango; Juan Manuel Galarza S; Washington Fierro Saltos; Juan Sosa Silva Digna Rocio Mejia Caguana; Carlos Jeovanny Tacle Estrada; Benavides Selllán Luis Ernesto; Sofía Verónica Vásconez Miranda

- Observe sí la mala ortografía afecta a la articulación del lenguaje y si la conoce.

- Corrija meticulosamente las producciones escritas del estudiante.

- Constate las habilidades perceptivas, memoria auditiva, pruebas de reproducción de ritmos, repetición de dígitos o series de palabras y letras. En la memoria visual se evalúa a través de la reproduccón de ejemplos gráficos, figuras o signos.

- Habilidades lingüísticas, establecer diálogos con el estudiante y registrar fonemas y articulaciones para probar si se distorsionan fonema-grafema en la escritura.

- Habilidades lógico-intelectuales, corresponde a la evaluación del nivel de inteligencia.

Para este diagnóstico se recomienda aplicar algunas técnicas como por ej.: Dictado, Copia de texto con otro tipo de letra, copia fiel de un texto y elaborar composiciones.

En el Capítulo III, artículo 6. De la Ley de Educación dice que "Los niños, niñas y adolescentes con discapacidad tienen derecho a la inclusión en el sistema educativo, en la medida de su nivel de discapacidad. Todas las unidades educativas están obligadas a recibirlas y a crear los apoyos y adaptaciones físicas, pedagógicas, de evaluación y promoción adecuados a sus necesidades.”

Según el sitio web (Ecu Red) expone el siguiente concepto de recursos didácticos.

Los Recursos didácticos son mediadores para el desarrollo y enriquecimiento del proceso de enseñanza - aprendizaje, que cualifican su dinámica desde las dimensiones formativa, individual, preventiva, correctiva y compensatoria, que 


\section{Los transtorno del aprendizaje y el modelo pedagógico invertido}

Vol. 2, núm. 2., (2018)

Digna Rocio Mejia Caguana; Carlos Jeovanny Tacle Estrada; Benavides Selllán Luis Ernesto;

Sofía Verónica Vásconez Miranda

expresan interacciones comunicativas concretas para el diseño y diversificación de la actuación del docente. Identificando los problemas de aprendizaje se dará cumplimiento a los reglamentos ministeriales educativos.

\section{Metodología.}

Para fundamentar el hecho científico se tomó el método descriptivo, estableciendo diferencias entre los transtornos de la lectoescritura y las falencias gramaticales existentes. Con el método explicativo, para determinar los orígenes de las jergas regionales y las que han sido establecidas dentro del diccionario español. Se utilizó las técnicas cuantitativas para recopilar la información, obtener resultados estadísticos, fijando el uso de instrumentos como es la encuesta y la entrevista dirigida a la comunidad educativa.

Se tomó la taxonomía de Bloom, para señalar la dimensión cognitiva del modelo de aula invertida a través de las fases del ciclo de aprendizaje.

- Conocimiento: Asimilar y recordar información previa.

- Comprensión: Representación de la información percibida.

- $\quad$ Aplicación: Prácticar en nuevas situaciones.

- Análisis: Analizar posibles soluciones. 


\section{Los transtorno del aprendizaje y el modelo pedagógico invertido}

Vol. 2, núm. 2., (2018)

Rodrigo del Pozo Durango; Juan Manuel Galarza S; Washington Fierro Saltos; Juan Sosa Silva Digna Rocio Mejia Caguana; Carlos Jeovanny Tacle Estrada; Benavides Selllán Luis Ernesto; Sofía Verónica Vásconez Miranda

- Síntesis: Crear, integrar, combinar ideas, planear y proponer nuevas estrategias.

- $\quad$ Evaluación: Emisión de juicios.

La investigación bibliográfica para solventar el trabajo con las teórias expuestas por científicos pedagogos, filosófos y psicólogos. Tal y como hizo Lev Vygotsky, Albert Bandura también centra el foco de su estudio sobre los procesos de aprendizaje en la interacción entre el aprendiz y el entorno.

Tabla 1.- Matriz Operacionalización de Variables

\begin{tabular}{|c|c|c|}
\hline VARIABLE & DIMENSIÓN & INDICADORES \\
\hline \multirow{3}{*}{$\begin{array}{l}\text { LA } \\
\text { LECTOESCRITURA }\end{array}$} & $\begin{array}{l}\text { Transtornos } \quad y \\
\text { falencias }\end{array}$ & Definición - Importancia - Clasificación \\
\hline & Orígenes & Factores - Dificultades - Causas \\
\hline & $\begin{array}{l}\text { Identificación } \\
\text { de Problemas }\end{array}$ & Diagnóstico - Detección - Tratamiento \\
\hline \multirow[b]{2}{*}{ AULA INVERTIDA } & $\begin{array}{ll}\text { Modelo de } \\
\text { aprendizaje }\end{array}$ & Definición - Importancia - Objetivo \\
\hline & $\begin{array}{l}\text { Teorías } \\
\text { Del } \\
\text { Aprendizaje }\end{array}$ & $\begin{array}{l}\text { Teorias de Lev Vygotsky } \\
\text { Albert Bandura y las Técnicas de aprendizaje } \\
\text { social (TAS) }\end{array}$ \\
\hline \multirow{2}{*}{$\begin{array}{l}\text { Entorno } \\
\text { Web } \\
\text { Educativo }\end{array}$} & $\begin{array}{l}\text { Material } \\
\text { Didáctico }\end{array}$ & $\begin{array}{l}\text { Recursos multimedia } \\
\text { Redes sociales } \\
\text { Entornos web }\end{array}$ \\
\hline & Características & $\begin{array}{l}\text { Diseño - Contenido - Estructura - Estrategia } \\
\text { Técnicas }\end{array}$ \\
\hline
\end{tabular}




\section{Los transtorno del aprendizaje y el modelo pedagógico invertido}

Vol. 2, núm. 2., (2018)

Digna Rocio Mejia Caguana; Carlos Jeovanny Tacle Estrada; Benavides Selllán Luis Ernesto;

Sofía Verónica Vásconez Miranda

\begin{tabular}{|l|l|l|}
\hline & Blogs \\
& Tipos & Sitios web \\
Plataformas web 3.0
\end{tabular}

\section{Resultados.}

Mediante los resultados obtenidos de las encuestas planteadas a docentes y estudiantes por medio de la investigación de campo que se realizó se ha podido establecer la influencia que tiene la disortografía en la asignatura de lengua y literatura, como objetivo se plantea proporcionar métodos y técnicas para el aprendizaje ortográfico.

Se puede decir que en términos generales la disortografía no es un término familiar, pero los síntomas no son raros, especialmente en los estudiantes cuando están aprendiendo a escribir, lo importante es prestar atención y brindar la ayuda oportuna a quienes presenten estas anomalías en la escritura y ortografía.

\section{Discusión.}

Las investigaciones sobre psicogénesis de la lengua escrita han puesto de manifiesto que las producciones de los niños no son caprichosas, que podemos descubrir en ellas reglas que las orientan, principios que las justifican.

Bergmann y Sams idearon una solución para evitar que los alumnos perdieran clases por ejemplo, por enfermedad, para ello grababan los contenidos a impartir y los distribuían entre 


\section{Los transtorno del aprendizaje y el modelo pedagógico invertido}

Vol. 2, núm. 2., (2018)

Rodrigo del Pozo Durango; Juan Manuel Galarza S; Washington Fierro Saltos; Juan Sosa Silva Digna Rocio Mejia Caguana; Carlos Jeovanny Tacle Estrada; Benavides Selllán Luis Ernesto; Sofía Verónica Vásconez Miranda

sus alumnos para que los visualizaran en casa antes de la clase, el trabajo en el aula consistía en realizar proyectos para poner en práctica los conocimientos.

La lectoescritura, requiere de un plan de entrenamiento y aprendizaje formal aún cuando algunas disciplinas pedagógicas claman una adquisición igualmente espontánea basada en la necesidad de expresarse gráficamente. Aspectos como la atención, la memoria, el desarrollo del lenguaje, las hablidades visoperceptuales y las praxias motoras constituyen la base de los procesos de aprendizaje.

Por otro lado, el avance de la tecnología en el campo de la comunicación y de la información, se argumentó, en algún momento, que la imagen y la palabra hablada reemplazarían ventajosamente a la lectura y la escritura; sin embargo, la realidad demuestra que la habilidad lectora y la producción escrita cobran mayor vigencia en el mundo globalizado. Es importante resaltar que no basta con leer mecánicamente, sino desarrollar las habilidades que permitan comprender, seleccionar, organizar, procesar y utilizar la información

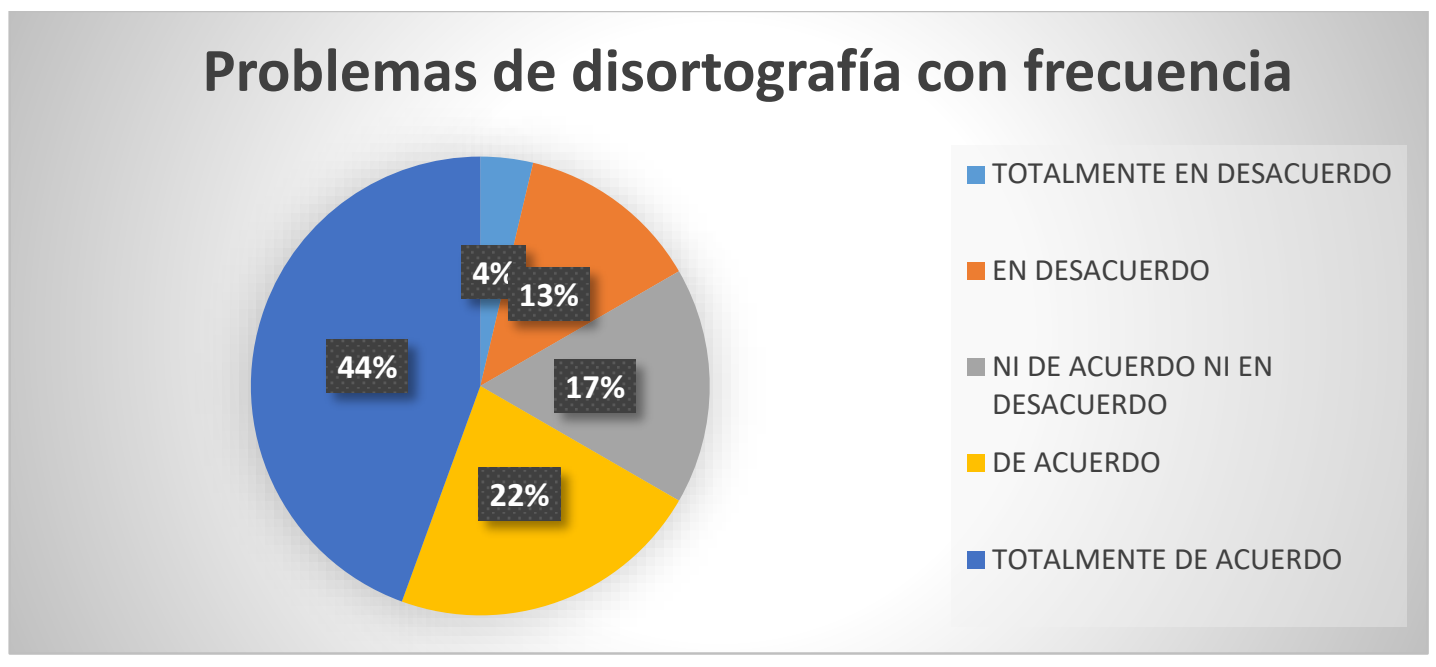

Revista Científica Mundo de la Investigación y el Conocimiento. 2 (2). pp. 194-208 


\section{Los transtorno del aprendizaje y el modelo pedagógico invertido}

Vol. 2, núm. 2., (2018)

Digna Rocio Mejia Caguana; Carlos Jeovanny Tacle Estrada; Benavides Selllán Luis Ernesto;

Sofía Verónica Vásconez Miranda

\section{Gráfico 1. Problemas de disortografía}

Fuente: Levantamiento de información U.E. F. "Dr. Migule Donoso Pareja"

\section{Conclusiones.}

Una vez tabulados los datos de las encuestas, se estableció que la creación del material didáctico en línea servirá de gran ayuda para que el estudiante tenga un aprendizaje óptimo. El material didáctico en línea que se creará será utilizado por los estudiantes, que no logran captar totalmente las reglas ortográficas con el fin de mejorar el léxico en los estudiantes. De la misma manera fortalecerá al docente, para mejorar la calidad de enseñanza-aprendizaje, fomentando la lectoescritura.

La competencia en la gramática y la sintaxis de una lengua facilita la identificación de las palabras. Ayuda a comprender las oraciones y a utilizar el contexto oracional, colabora en el proceso de asignar a las palabras escritas lo que podríamos denominar códigos de función, estos son especialmente importantes a la hora de distinguir entre palabras funcionales, carentes de contenido. El conocimiento de las reglas de producción morfofonémica es una forma en que la competencia sintáctica y gramatical ayuda a la identificación de las palabras escritas.

\section{Bibliografía.}

Ajuriaguerra, A. (1973). La escritura del niño. Barcelona: Laia.

Arduini, R., Aparecida Capellini, S., \& Ciasca, S. (2006). Comparative study of the neuropsychological and neuroimaging evaluations in children with dyslexia. Arquivos de Neuro-Psiquiatria, 64(2), 369-375. 


\section{Los transtorno del aprendizaje y el modelo pedagógico invertido}

Vol. 2, núm. 2., (2018)

Rodrigo del Pozo Durango; Juan Manuel Galarza S; Washington Fierro Saltos; Juan Sosa Silva

Digna Rocio Mejia Caguana; Carlos Jeovanny Tacle Estrada; Benavides Selllán Luis Ernesto;

Sofía Verónica Vásconez Miranda

Guevara Benítez, Y., López H, A., \& García V, G. (2008). Habilidades de lectura en primer grado en alumnos de estrato sociocultural bajo. Revista Mexicana de Investigación Educativa, 13(37), 573-597.

Posada, J. (1993). JEROME BRUNER Y LA EDUCACION DE ADULTOS. En UNESCO, Proyecto Principal de Educacion en America Latina (págs. 49-54). Satiago: La Organización de las Naciones Unidas para la Educación, la Ciencia y la Cultura. 